\begin{tabular}{|c|ccc|c|}
\hline & PORT SAID ENGINEERING RESEARCH JOURNAL \\
\hline
\end{tabular}

\title{
THERMAL PERFORMANCE of DIFFERENT GAS TURBINE CYCLES
}

\section{ABSTRACT}

\author{
ALY KAMELABD El-SAMED ${ }^{l}$
}

The performance of seven different gas turbine cycles are investigated versus the change of the gas turbine inlet temperature (TIT) which ranged from $773 \mathrm{~K}$ to $1373 \mathrm{~K}$ keeping ambient air temperature $294 \mathrm{~K}$, pressure ratio 9 and air flow rate $37 \mathrm{~kg} / \mathrm{s}$ constant. The corresponding performances are expressed in terms of: fuel consumption rate, power output, thermal efficiency and specific power output for the seven cycles. From the results it is found that both of the turbine inlet temperature (TIT) and cycle arrangement have a great effect on the thermal performance of the gas turbine cycle. At the maximum turbine inlet temperature (TIT) $1373 \mathrm{~K}$, it is found that the highest obtainable power output is produced by the modified cycle 4 while the highest obtainable efficiency is produced by the modified cycle 6 .

KEYWORDS: Gas Turbine, Performance, Power, Efficiency.

\section{INTRODUCTION}

The use of gas turbines in the power generation, power industry and petrochemical has increased very quickly in the last years. The last 20 years has seen a large growth in gas turbine technology. The growth is spearheaded by the growth of materials technology, new coatings and new cooling schemes. This, with the conjunction of increase in compressor pressure ratio, has increased the gas turbine thermal efficiency [1,2], from about $15 \%$ to $45 \%$ [3]. The performance of the power plant strongly depends on ambient air temperature. As the inlet air temperature decreases the power output and efficiency increases [4-10]. A parametric study of the effect of pressure ratio, a mbient temperature, ambient relative humidity, effectiveness of the recuperated heat exchanger on the performance of gas turbine cycles are studied [11]. The study indicates that using two stages of cooling in the intercooler boost the gain in efficiency and applying absorption inlet cooling could increase the efficiency of the cycle by up to $6.6 \%$. The power output of the gas turbine is a function of turbine inlet temperature which is fixed due to the metallurgical problem of turbine blade cooling. As the gas turbine inlet temperature increases the output power and efficiency increases $[12,13]$

The simple gas turbine itself is less efficient due to high temperature of the combustion gas leaving as exhaust from the turbine. This has led to the introduction of various modifications to the gas turbine design. Six different modified types/arrangements of gas turbine cycles are considered in this study. The performance of these cycles are calculated and determined versus the change of the turbine inlet temperature (TIT) from $500^{\circ} \mathrm{C}(773 \mathrm{~K})$ through $1100^{\circ} \mathrm{C}$ $(1373 \mathrm{~K})$, which increases by increasing the fuel flow rate consumption. For the purpose of comparatively evaluation and analysis of the seven gas turbine cycles,

${ }^{T}$ Mechanical Power Engineering Department, Faculty of Engineering, Port-Said University the simple Brayton gas turbine cycle is considered as the basis case. An existing small gas turbine power plant is considered as a source of the operating conditions, which are: air mass flow rate $37 \mathrm{~kg} / \mathrm{s}$, compressor pressure ratio 9 and calorific value of the fuel $41800 \mathrm{~kJ} / \mathrm{kg}$. The following parameters in Table-1 are calculated and derived based on the operating data of the simple gas turbine power plant taking into consideration the specific heat capacity of the flue gases and air are calculated as a function of the temperature [2,14].

\begin{tabular}{|c|c|c|}
\hline \multicolumn{3}{|c|}{ Table-1 } \\
\hline $\begin{array}{l}\eta_{\text {ssor }}=82 \% \\
\text { isentropicjompre }\end{array}$ & $\eta_{\text {combustion }}$ & chamber $=$ \\
\hline $\begin{array}{l}\eta_{\text {isentropic)gas }} \\
\text { turbine }=85 \%\end{array}$ & $\begin{aligned} & \eta \text { mechanical } \text {. } \\
\text { generator }= & 90 \%\end{aligned}$ & $\eta$ electric \\
\hline
\end{tabular}

Keeping the above operating conditions and the parameters in Table- 1 constant, the performance of each gas turbine cycle is calculated using MATLAB software and expressed in terms of:

a) Fuel flow rate consumption,

b) Power output,

c) Thermal efficiency,

d) Work ratio,

e) Exhaust gas temperature,

f) Specific power output.

\section{THE CONSIDERED GAS TURBINE CYCLES}

Each of the considered gas turbines cycles (seven) is shown as a flow diagram and representation on T-s diagram accompanied with the related equations as follows: 


\subsection{The Simple Gas Turbine Cycle (Cycle1)}
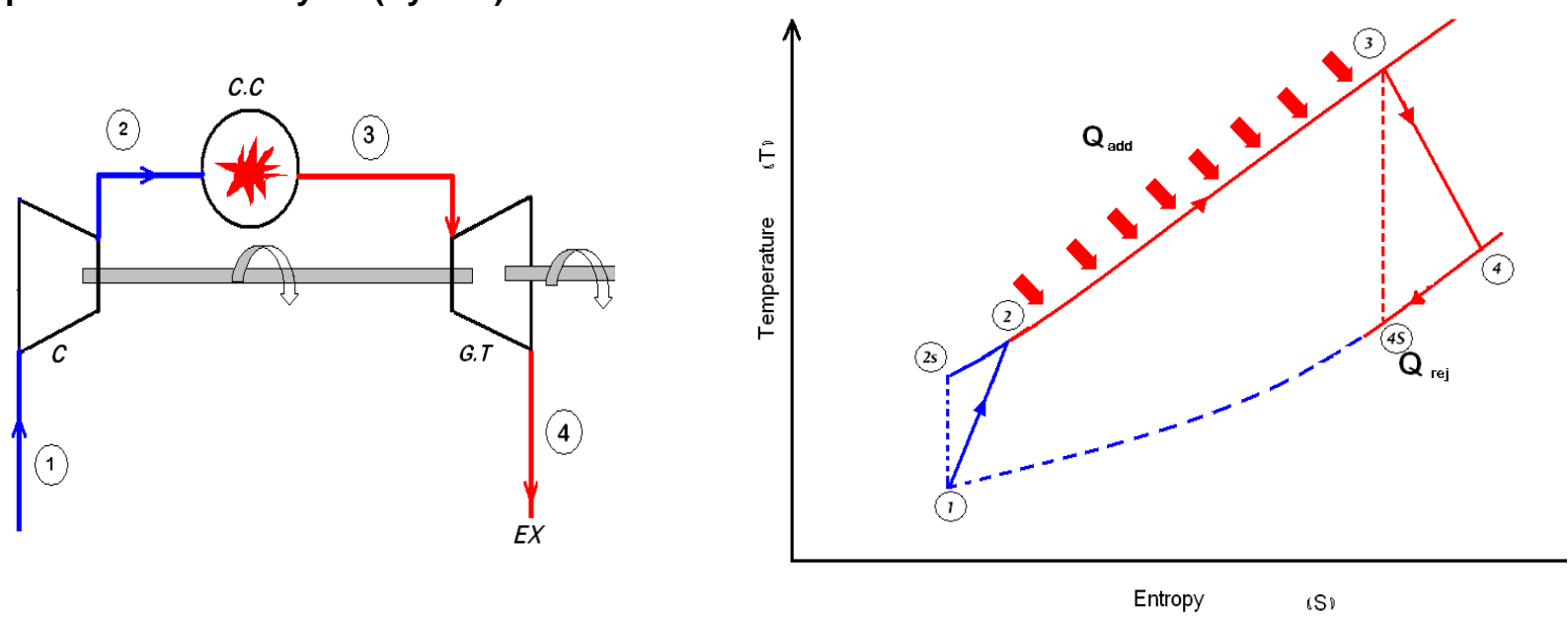

Fig.1(a) The Flow Diagram of the Simple Gas Turbine Cycle.
Fig.1(b) Representation of The Simple Gas Turbine Cycle on T-S diagram.

The main equations are:

$$
\text { Power }_{G T}=\left(\dot{m}_{a}+\dot{m}_{f}\right) C_{P g}\left(T_{4}-T_{3}\right)+\dot{m}_{a} C_{P a}\left(T_{2}-T_{1}\right) \quad k \mathrm{~W}
$$

Power $_{\text {net }) G T}=\left[\left(\dot{m}_{a}+\dot{m}_{f}\right) C_{P g}\left(T_{4}-T_{3}\right)+\dot{m}_{a} C_{P a}\left(T_{2}-T_{1}\right)\right] \eta_{\text {mec } h) G T} \eta_{E G} \quad k \mathrm{~W}$

$\dot{m} f=\frac{\left(\dot{m}_{a}+\dot{m}_{f}\right) C_{P g} T_{3}-\dot{m}_{a} C_{P a} T_{2}}{C . V . \times \eta_{c c}} \mathrm{~kg} / \mathrm{s}$

Qaidd $=\left(\dot{m}_{a}+\dot{m}_{f}\right) C_{P g} T_{3}-\dot{m a} C_{P a} T_{2} \quad k W$

$\eta_{\text {th }) \mathrm{GT}}=\frac{- \text { Power }_{G T}}{\text { Qaidd }}$

work ratio $=\frac{- \text { Power }_{G T}}{- \text { gross Power of Gas Turbine }}$

work ratio $=\frac{-\left(\dot{m}_{a}+\dot{m}_{f}\right)\left[C p_{g}\left(T_{4}-T_{3}\right)+\dot{m}_{a} C p_{a}\left(T_{2}-T_{1}\right)\right]}{-\left[\left(\dot{m}_{a}+\dot{m}_{f}\right) C p_{g}\left(T_{4}-T_{3}\right)\right]}$

Specific Power output $=\frac{- \text { Power }_{\text {net }) G T}}{\dot{m}_{f} \times 3600} \quad \mathrm{~kW} . \mathrm{h} / \mathrm{kg}$

The modified gas turbine cycles are as follows:

\subsection{The Simple Gas Turbine Cycle With Series Turbine (Cycle2)}

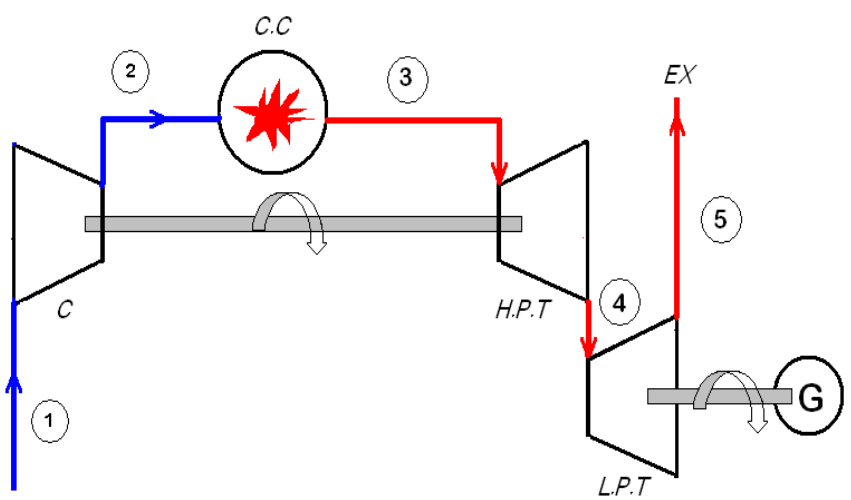

Fig.2(a) The Flow Diagram of the Simple Gas Turbine Cycle with Series Turbine.

The comple mentary equations are:

Power $_{\text {net }) \mathrm{GT}}=\left(\dot{m}_{a}+\dot{m}_{f}\right) C_{P g}\left(T_{5}-T_{4}\right) \eta_{\text {mec } h) G T} \eta_{E G}$

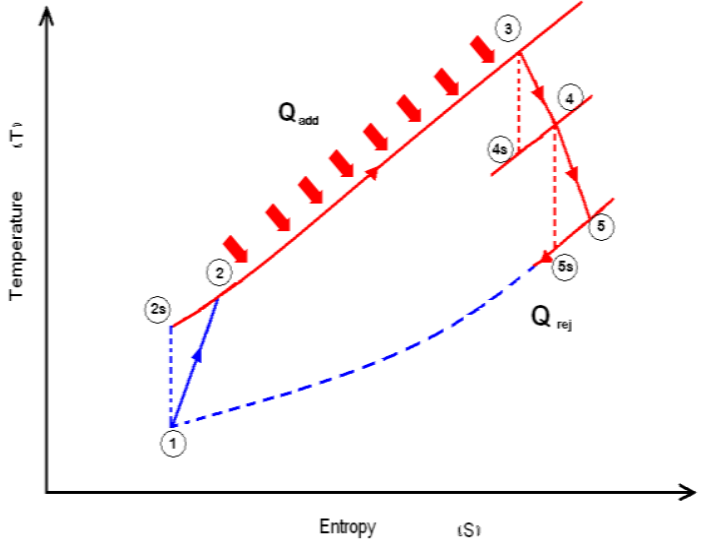

Fig.2(b) Representation of the Simple Gas Turbine Cycle with Series Turbine on " $\mathbf{T}-\mathbf{s}$ " Diagram. 
$\eta_{\text {th }) \mathrm{GT}}=\frac{- \text { Power }_{G T}}{\text { Q add }}=\frac{-\left(\dot{m}_{a}+\dot{m}_{f}\right) C_{P_{g}}\left(T_{5}-T_{4}\right)}{\left(\dot{m}_{a}+\dot{m}_{f}\right) C_{P_{g}} T_{3}-\dot{m}_{a} C_{P_{a}} T_{2}}$

Work ratio $=\frac{- \text { Power }_{G T}}{- \text { gross power of gas turbines }}$

Work ratio $=\frac{-\left(\dot{m}_{a}+\dot{m}_{f}\right) C_{P_{g}}\left(T_{5}-T_{4}\right)}{-\left(\dot{m}_{a}+\dot{m}_{f}\right)\left[\left(C_{P_{g}}\left(T_{4}-T_{3}\right)+C_{P_{g}}\left(T_{5}-T_{4}\right)\right]\right.}$

2.3. The Simple Gas Turbine Cycle with Series Turbine and Two-Stages Compressor (Cycle3)

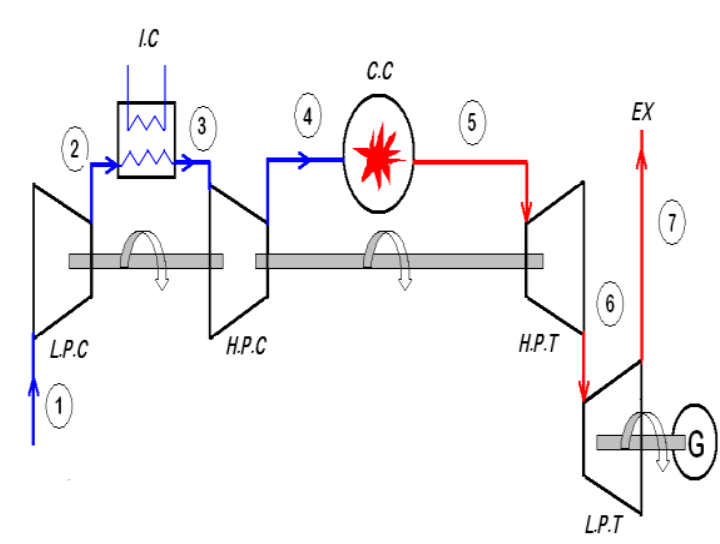

Fig.3 (a) The Flow Diagram of The Simple Gas Turbine Cycle with Series Turbine and two-stage Compressor.

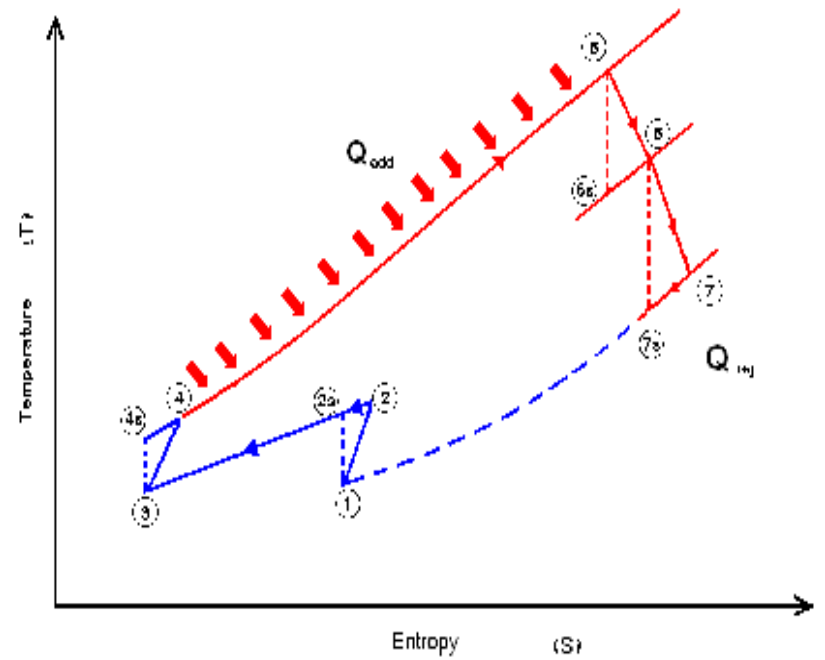

Fig.3(b) Representation of The Simple Gas Turbine Cycle with Series Turbine and two-stage Compressor on" T-S" Diagram.

The complementary equations are;

Power $_{\text {net }) \mathrm{GT}}=\left(\dot{m}_{a}+\dot{m}_{f}\right) C_{P_{g}}\left(T_{7}-T_{6}\right) \eta_{\text {mec } h) G T} \eta_{E G} \quad \mathrm{~kW}$

2.4. The Simple Gas Turbine Cycle with Reheat and Two-Stage Compressor (Cycle4)

The complementary equations are:

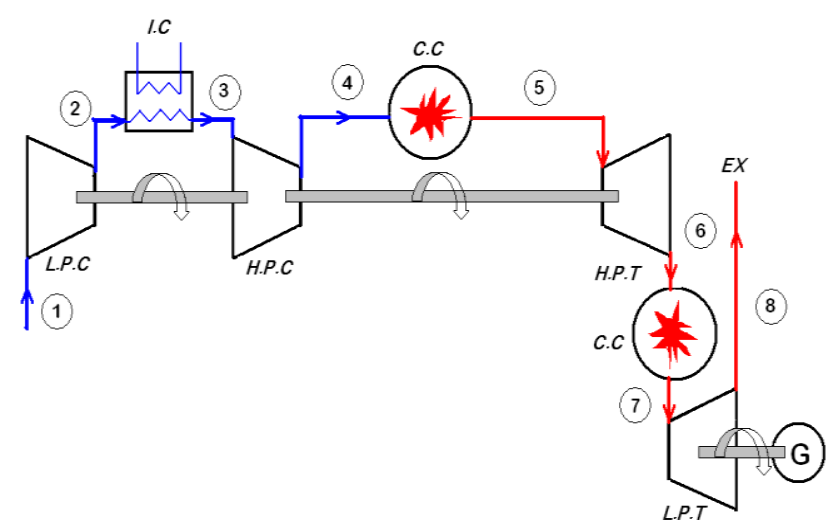

Fig.4(a) The Flow Diagram Of The Simple Gas Turbine Cycle with Reheat and Two-Stage Compressor.

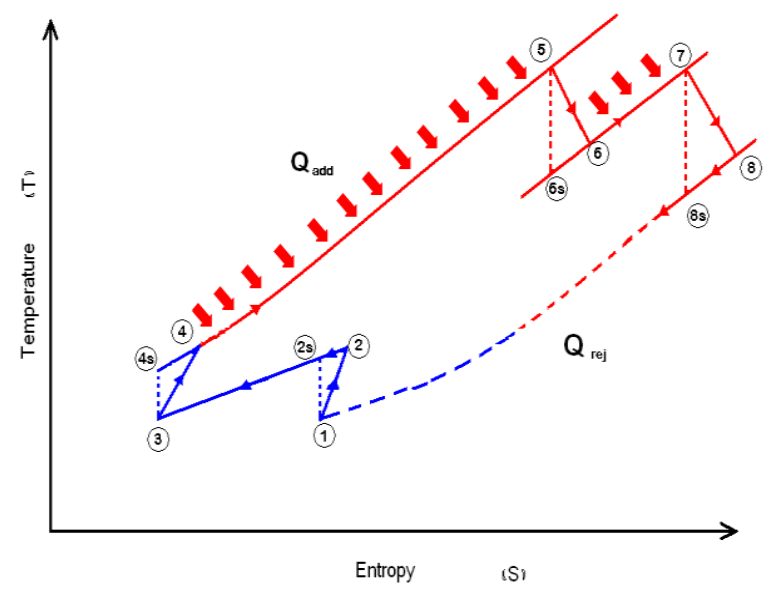

Fig.4(b) Representation of The Simple Gas Turbine Cycle with Reheat and Two-Stage Compressor on" $T$ $-\mathrm{S}$ " Diagram .

$\dot{m}_{f}=\dot{m}_{f 1}+\dot{m}_{f 2}$

Power $_{\text {H.P.T }}=\left(\dot{m}_{a}+\dot{m}_{f 1}\right) C_{P_{g}}\left(T_{6}-T_{5}\right)=2 \dot{m}_{a} C_{P_{a}}\left(T_{2}-T_{1}\right) \quad k W$

Power $_{\text {net }) \mathrm{GT}}=\left(\dot{m}_{a}+\dot{m}_{f 1}+\dot{m}_{f 2}\right) C_{P_{g}}\left(T_{8}-T_{7}\right) \eta_{\text {mec } h) G T} \eta_{E G} \quad k W$ 
$\eta_{\mathrm{th}) \mathrm{GT}}=\frac{- \text { Power }_{G T}}{Q \dot{a} d d}=\frac{-\left(\dot{m}_{a}+\dot{m}_{f 1}+\dot{m}_{f 2}\right) C_{P_{g}}\left(T_{8}-T_{7}\right)}{\left.\left(\dot{m}_{a}+\dot{m}_{f 1}\right) C_{P_{g}} T_{5}-\dot{m}_{a} C_{P_{a}} T_{4}+\left(\dot{m}_{a}+\dot{m}_{f 1}+\dot{m}_{f 2}\right) C_{P_{g}} T_{7}-\left(\dot{m}_{a}+\dot{m}_{f 1}\right) T_{6}\right)}$

\subsection{The Simple Gas Turbine Cycle with Series Turbine and Two-Stage Compressor and Heat Exchanger (Cycle5)}

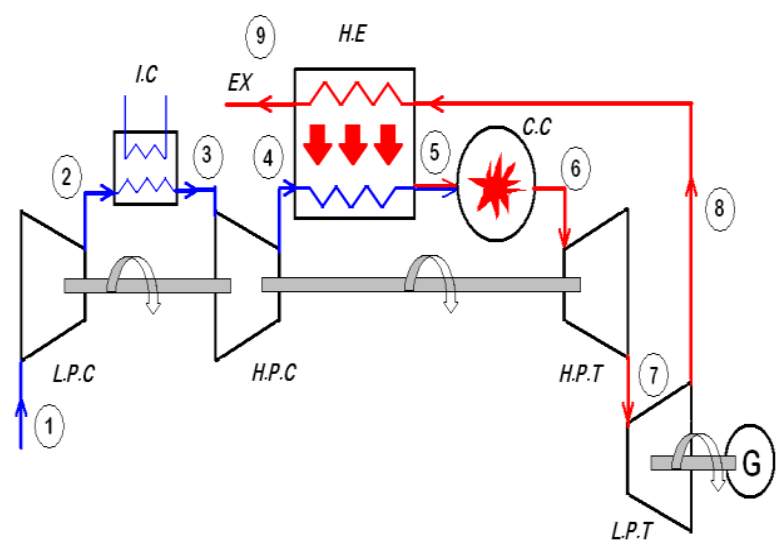

Fig.5(a) The Flow Diagram of The Simple Gas Turbine Cycle with Series Turbine and twostage Compressor and Heat Exchanger.

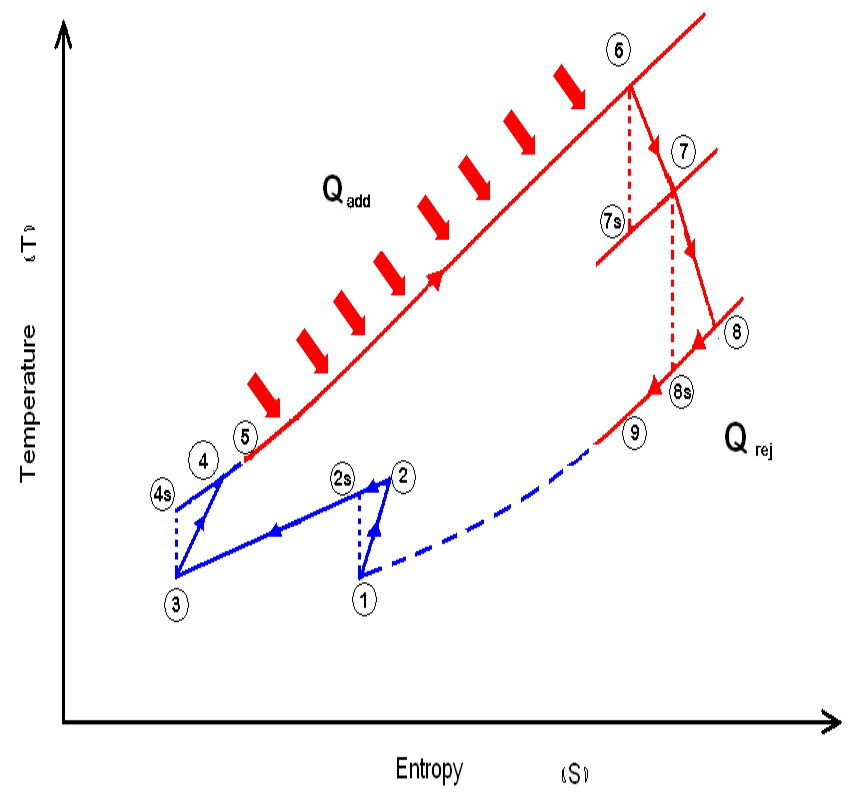

Fig.5(b) Representation of The Simple Gas Turbine Cycle with Series Turbine and two-stage Compressor and Heat Exchanger on" T-S" Diagram.

From the literature survey, the mean value of the heat exchanger effectiveness is taken $0.72[2,3]$ and considered to be constant for the diffe rent cycles .

The complementary equations are:

$T_{3}=T_{1}, T_{4}=T_{2}, T_{6}=T_{\max }$
Effectiveness $=\frac{\dot{m}_{a} C_{p_{a}}\left(T_{5}-T_{4}\right)}{\left(\dot{m}_{a}+\dot{m}_{f}\right) C_{p_{g}}\left(T_{8}-T_{4}\right)}$

Heat balance for heat exchanger;

$$
\begin{array}{rl}
\dot{m}_{a} C_{p_{a}}\left(T_{5}-T_{4}\right)=\left(\dot{m}_{a}+\dot{m}_{f}\right) C_{p_{g}}\left(T_{8}-T_{9}\right) & \\
\text { Power }_{\text {net }) \mathrm{GT}}=\left(\dot{m}_{a}+\dot{m}_{f}\right) C_{P_{g}}\left(T_{8}-T_{7}\right) \eta_{\text {mec } h) G T} \eta_{E G} \quad k W & k W \\
\eta_{\text {th }) \mathrm{GT}}= & \frac{- \text { Power }_{G T}}{\text { Qadd }}=\frac{-\left(\dot{m}_{a}+\dot{m}_{f}\right) C_{P_{g}}\left(T_{8}-T_{7}\right)}{\left(\dot{m}_{a}+\dot{m}_{f}\right) C_{P_{g}} T_{6}-\dot{m}_{a} C_{P_{a}} T_{5}}
\end{array}
$$

2.6. The Simple Gas Turbine Cycle with Reheat and Two-Stage Compressor and Heat Exchanger (Cycle6)
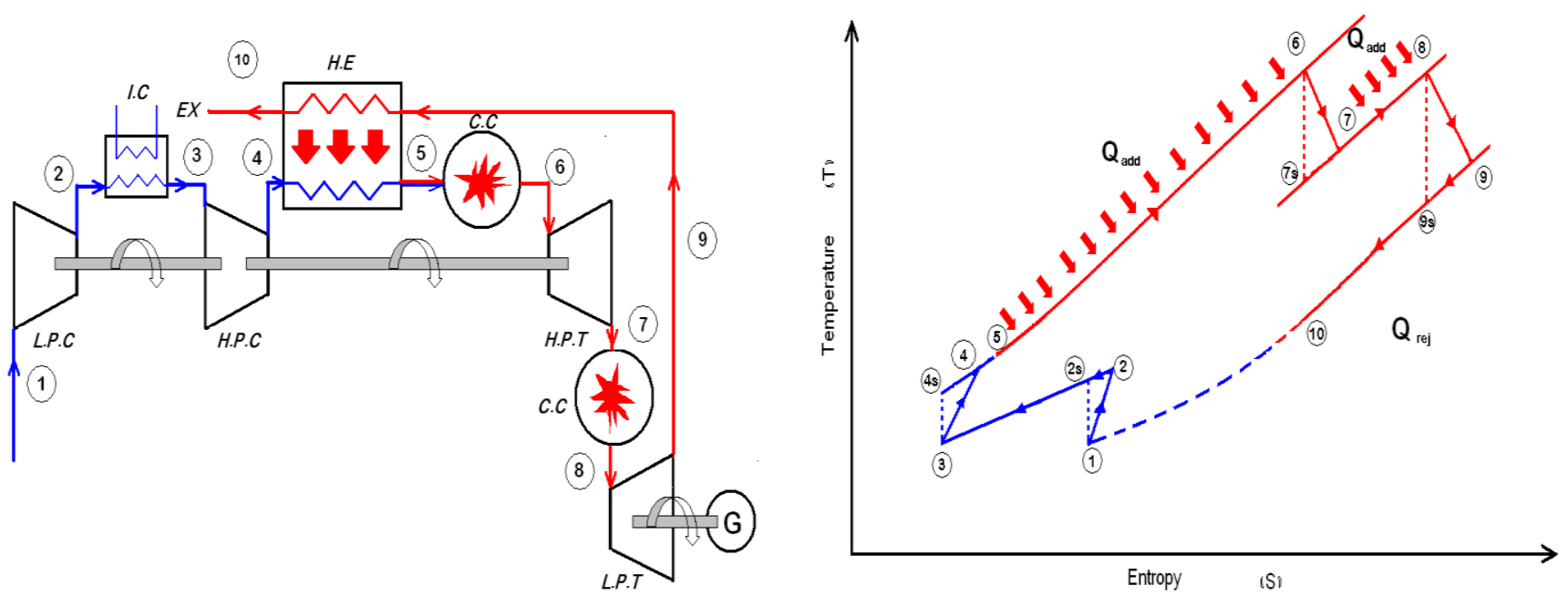
Fig.6(a) The Flow Diagram of The Simple Gas Turbine Cycle with Reheat and Two-Stage Compressor and Heat Exchanger.
Fig.6(b) Representation of The Simple Gas Turbine Cycle with Reheat and Two-stage Compressor and Heat Exchanger on "T-S" Diagram.

The complementary equations are:

$T_{6}=T_{8}=T_{\max }$

Heat balance for heat exchanger;

$\dot{m}_{a} C_{p_{a}}\left(T_{5}-T_{4}\right)=\left(\dot{m}_{a}+\dot{m}_{f 1}+\dot{m}_{f 2}\right) C_{p_{g}}\left(T_{9}-T_{10}\right)$

$\dot{m}_{f}=\dot{m}_{f 1}+\dot{m}_{f 2}$

Power $_{\text {net }) \mathrm{GT}}=\left(\dot{m}_{a}+\dot{m}_{f 1}+\dot{m}_{f 2}\right) C_{P_{g}}\left(T_{9}-T_{8}\right) \eta_{\text {mec } h) G T} \eta_{E G} \quad k W$
$\eta_{\text {th }) \mathrm{GT}}=\frac{- \text { Power }_{G T}}{\text { Q } \dot{a d d}}=\frac{-\left(\dot{m}_{a}+\dot{m}_{f 1}+\dot{m}_{f 2}\right) C_{P_{g}}\left(T_{9}-T_{8}\right)}{\left(\dot{m}_{a}+\dot{m}_{f 1}\right) C_{P_{g}} T_{6}-\dot{m}_{a} C_{P_{a}} T_{5}+\left(\dot{m}_{a}+\dot{m}_{f 1}+\dot{m}_{f 2}\right) C_{P_{g}} T_{8}-\left(\dot{m}_{a}+\dot{m}_{f 1}\right) C_{P_{g}} T_{7}}$

2.7. The Parallel Flow Gas Turbine Cycle with Two-Stage Compressor and Heat Exchanger (Cycle7)

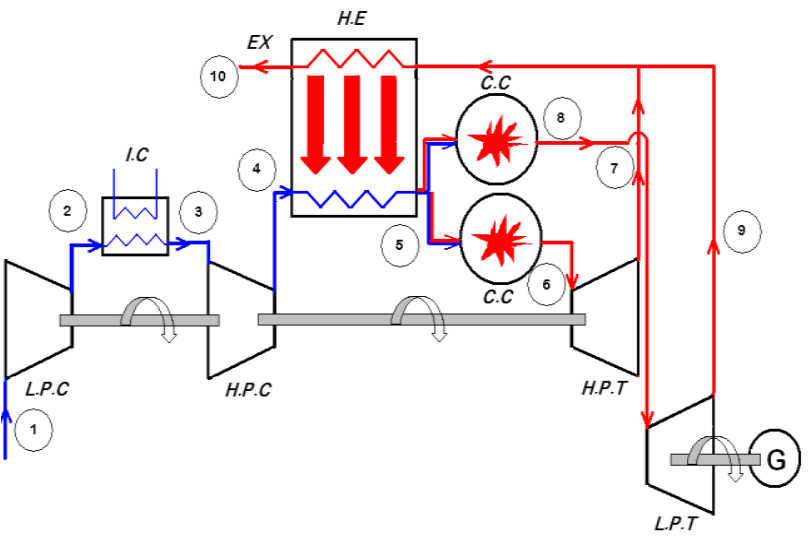

Fig.7(a) The Flow Diagram of The Parallel Flow Gas Turbine Cycle with Two-Stage Compressor and Heat Exchanger.

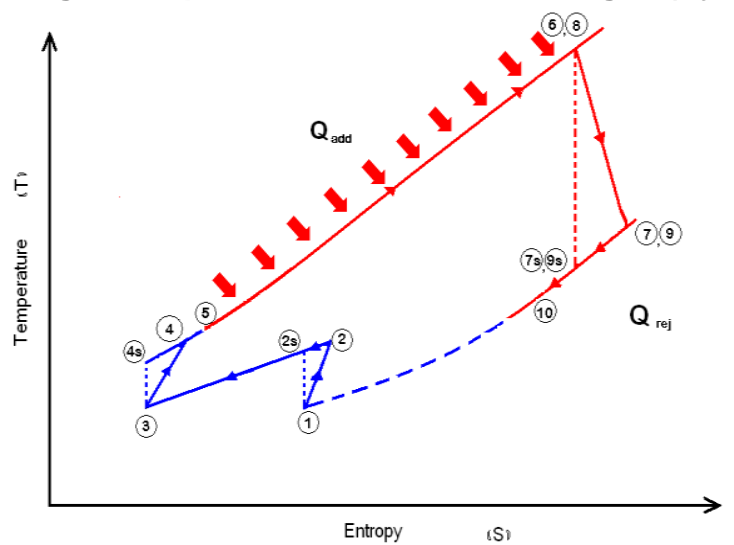

Fig.7(b) Representation of The Parallel Flow Gas Turbine Cycle with Two-Stage Compressor and Heat Exchanger on" T-S" Diagram .

The comple mentary equations are:

$T_{6}=T_{8}=T_{\max }$

$T_{7}=T_{9}$

$\dot{m}_{a}=\dot{m}_{a) c c 1}+\dot{m}_{a) c c 2}$

Power $)_{\text {net GT }}=\left(\dot{m}_{a) c c 2}+\dot{m}_{f) c c 2}\right) C_{P_{g}}\left(T_{9}-T_{8}\right) \eta_{\text {mech }) \mathrm{GT}} \eta_{\mathrm{EG}} \quad k W$

$\eta_{\mathrm{th}) \mathrm{GT}}=\frac{- \text { Power })_{G t}}{Q_{a d d}}=\frac{-\left(\dot{m}_{a 2}+\dot{m}_{f 2}\right) C_{P_{g}}\left(T_{9}-T_{8}\right)}{\left.\left(\left(\dot{m}_{a) c c 1}+\dot{m}_{f) c c 1}\right) C_{P_{g}} T_{6}-\dot{m}_{a) c c 1} C_{P_{a}} T_{5}\right)+\left(\dot{m}_{a) c c 2}+\dot{m}_{f) c c 2}\right) C_{P_{g}} T_{8}-\dot{m}_{a) c c 2} C_{P_{a}} T_{5}\right)}$

\section{RESULTS}

\subsection{Fuel Consumption of the Different Gas Turbine Cycles}

The increase of the turbine inlet temperature is occurred as a result of increasing the fuel consumption rate (keeping the air mass flow rate constant). Figure 8(a) shows that, as the turbine inlet temperature increases from $737 \mathrm{~K}$ to $1373 \mathrm{~K}$, the corresponding comparatively required mass flow rate consumption for all the gas turbine cycles increases gradually with straight line relations. Generally, for the different turbine inlet temperatures the lowest fuel consumption rates are found to be for the gas turbine cycle7 and cycle5, while the highest values is found to be for cycle 4 . At turbine inlet temperature $1373 \mathrm{~K}$ the lowest fuel consumption rates are found to be $0.603 \mathrm{~kg} / \mathrm{s}$ and $0.61 \mathrm{~kg} / \mathrm{s}$ for cycle 7 and cycle 5 respectively while the highest value $1.24 \mathrm{~kg} / \mathrm{s}$ is found to be for cycle4 as clearly shown in Fig.8(b). So, at the maximum turbine inlet temperature $1373 \mathrm{~K}$ the fuel consumption rate of cycle1 (i.e. the basis simple gas turbine cycle) can be reduced due to the effect of adding the heat exchanger by $25 \%, 12 \%$ and $26 \%$ if cycle 5 , cycle 6 and cycle 7 are applied.

\subsection{Power Output of the Different Gas Turbine Cycles}

As the turbine inlet temperature increases from $773 \mathrm{~K}$ to $1373 \mathrm{~K}$, the net power output of the gas turbine cycles increases gradually in straight lines relations as shown in Fig.9(a) where their descending order are as follows; cycle4, cycle 6 , cycle 3 , cycle 5 , cycle 7 , cycle 1 , and cycle2. The highest comparative value is found to be for cycle 4 where it increases from $4 \mathrm{MW}$ to 14.2 
MW while for cycle 1 increases from $200 \mathrm{~kW}$ to 9.1 MW.

Running the gas turbine cycles at the maximum turbine inlet temperature $1373 \mathrm{~K}$, produce the highest values of the power output of 14.2 MW for cycle 4 and 12.7 MW for cycle6 while for cycle1 the power output is $9.1 \mathrm{MW}$. That means applying the modified cycle 4 and cycle 6 leads to an increase of power output by $56 \%$ and $39.56 \%$ respectively.

\subsection{Thermal Efficiency of the Different Gas Turbine Cycles}

As the turbine inlet temperature increases from $773 \mathrm{~K}$ to $1373 \mathrm{~K}$, it can be noticed from Fig.10(a) that, the thermal efficiency of the gas turbine cycles significantly increases in the form of two groups. For the first group which includes cycle3, cycle4, cycle1, and cycle 2 their thermal efficiencies increase slightly while for the second group which includes cycles 6,5 , and 7 their thermal efficiencies increase significantly producing the highest values. Figure 10(b) shows that the highest values of $46.0 \%, 43.5 \%, 41.86 \%$ are corresponding to cycle6, cycle5, and cycle 7 respectively when running at maximum inlet temperature $1373 \mathrm{~K}$, while the thermal efficiency for cycle 1 is low $28.57 \%$. So, the thermal efficiency of the simple gas turbine cycle (cycle1) can be increased by $61.0 \%, 52.26 \%$, and $46.52 \%$ if cycle 1 modified to become cycle 6 , cycle5, or cycle 7 respectively.

\subsection{Work Ratio of the Different Gas Turbine Cycles}

The work ratio is a term which deals with the negative effect of the compressor work on the power output. As expected, the trend and the order of the work ratio for the different gas turbine cycles versus the turbine inlet temperature is the same trend and the same order of the power output as shown in Figs.11(a), 11(b) compared with 9(a), 9(b). At the maximum turbine inlet temperature $1373 \mathrm{~K}$, the highest comparatively work ratio of 0.58 is found to be for cycle4 where its power output is also the highest value of 14.2 MW.

\subsection{Exhaust Gas Temperature of the Different Gas Turbine Cycles}

As the turbine inlet temperature increases from $773 \mathrm{~K}$ to $1373 \mathrm{~K}$, the exhaust gas temperature increases with straight lines relations. Again, there are two groups; the first group represents cycle6, cycle 7 , and cycle 5 where the incremental increase of the exhaust temperature are small (by about 95K) while for the second group which represents the rest of the cycles, the incremental increase are big (about 390K) as shown in Figs.12(a). That means for the first group, heat losses with the exhaust gases are smaller than those of the second group leading to higher thermal efficiency as seen in Fig.10(a,b). The highest exhaust gas temperature leaving the turbine is found to be $1032 \mathrm{~K}$ for cycle 4 as shown in Fig.12(b), that explain why the thermal efficiency of this cycle 4 is low $28.6 \%$ (which equal to the thermal efficiency of the simple basis cycle).

\subsection{Specific Power Output of the Different Gas Turbine Cycles}

Generally, the specific power output for the different gas turbine cycles increases as the turbine inlet temperature increases from $773 \mathrm{~K}$ to $1373 \mathrm{~K}$ as shown in Fig.13(a). At turbine inlet temperature 950K and above, it is noticed that the highest values of specific power output are found to be for cycle6, cycle 5, and cycle7 respectively. At the maximum turbine inlet temperature $1373 \mathrm{~K}$ the highest specific power output of $4.93 \mathrm{~kW} . \mathrm{h} / \mathrm{kg}$ is found to be for cycle 6 , while at the same temperature the minimum values of $3.08,3.08$, and $2.85 \mathrm{~kW} . \mathrm{h} / \mathrm{kg}$ are found to be for cycle 1 , cycle 4 and cycle 2 respectively as shown from Fig.13(b). Also, from Fig.13(a) it can be noticed that the curves divided into two groups; the first group includes cycles 5,6,7 while the second group includes cycles $1,2,3,4$. As TIT increases the specific power output of the first group cycles increases significantly and proportionally but for the second group it increases slightly and will be nearly constant above $1373 \mathrm{~K}$-by extrapolation. So, it is recommended to modify the simple cycle 1 to become cycle6 that will lead to an increase of the specific power output by $61 \%$.

\section{CONCLUSIONS}

1. The thermal performance curves of the seven diffe rent gas turbine cycles are obtained.

2. As the turbine inlet temperature (TIT) increases from $773 \mathrm{~K}$ to $1373 \mathrm{~K}$ the power output, the thermal efficiency and the specific power output increase for the seven cycles and reach their maximu malues at $1373 \mathrm{~K}$.

3. The highest thermal efficiency and the highest specific power output are found to be for the modified cycle 6 as their values increase from $12.5 \%$ to $46 \%$ and from $1.34 \mathrm{~kW} . \mathrm{h} / \mathrm{kg}$ to 4.93 $\mathrm{kW} . \mathrm{h} / \mathrm{kg}$ as the turbine inlet temperature increases from $773 \mathrm{~K}$ to $1373 \mathrm{~K}$ respectively. In other words at TIT $1373 \mathrm{~K}$ both of the thermal efficiency and the specific power output of the modified cycle 6 increase by $61 \%$ referred to cycle1.

4. Increasing the turbine inlet temperature as well as modifying the simple gas turbine cycle both of them have a great effect on increasing the power output, thermal efficiency and specific power output of the gas turbine cycles.

\section{NOMENCLATURE}

$$
\begin{aligned}
& w=\text { work, } \mathrm{kJ} / \mathrm{kg} \\
& \dot{m}=\text { flow rate }, \mathrm{kg} / \mathrm{s} \\
& \eta=\text { efficiency, } \% \\
& C_{P}=\text { specific heat capacit } \mathrm{y}, \mathrm{kJ} / \mathrm{kg} . \mathrm{K} \\
& T=\text { temperat ure, } \mathrm{K} \\
& q=\text { specific heat }, \mathrm{kJ} / \mathrm{kg} \\
& Q=\text { heat rate, } \mathrm{kJ} / \mathrm{s} \\
& \mathrm{EX}=\text { exhaust gases } \\
& \text { L.P.C. = Low pressure compressor } \\
& \text { H.P.C. }=\text { High pressure compressor } \\
& \text { I.C. }=\text { inter cooler } \\
& \text { H.E. = heat exchanger } \\
& \text { TIT }=\text { T urbine Inlet Temperat ure, } \mathrm{K}
\end{aligned}
$$




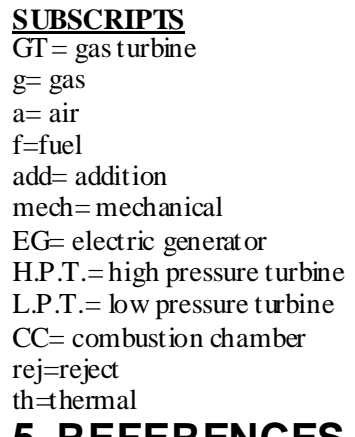

\section{REFERENCES}

1- Ibrahim T.K., Rahman M.M., "Effects of Operation Conditions on Performance of a Gas Turbine Power Plant" Procedia Engineering, 2010, Vol.15, pp: 4216-4223.

2- Rahman, M.M., Thamir K. Ibrahim, Taib, M.Y., Noor M.M., and Rosli A. Bakar "Thermal Analysis of Open Cycle Regenerative Gas Turbine Power Plant" World Academy of Science, Engineering and Technology, 2010, Vol.4, pp:1084-1089.

3- Meherwan P. Boyce, "Gas Turbine Engineering Handbook", second edition, 2002, Gu lf Publishing Company, Houston, Texas, USA.

4- Mohmood, F.G. and Mahdi, D.D. "A New Approach for Enhancing Performance of a Gas Turbine, Case Study: Khangiran Refinery" Applied Energy, 2009, Vol.86, pp: 2750-2759.

5- El Hadik, A.A., "The Impact of Atmospheric Conditions on Gas Turbine Performance" Journal of Engineering for Gas Turbines Power, Oct 01, 1990, 112(4), pp: 590-596

6- Kumar R.N. and Krishna R.K. "Improved Gas Turbine Efficiency Using Spray Coolers and
Through Alternative Regenerative Configuration, " ASME, Heat and Mas Transfer Conference, 2006, PP: 1819-1824.

7- Wang, F.J., and Chiou, J.S. " Integration of Steam Injection and Inlet Air Cooling for a Gas Turbine Generation System" Energy Conversion and Management, 2004, Vol.45, pp:15-26.

8- Kakaras E., Doukelis A., Prelipceana A. and Karellas S. " Inlet Air Cooling Methods for Gas Turbine Based Power Plants" ASME, J. Eng. Gas Turbine Power 2005, Vol.128(2), pp: 312-317.

9- Ameri, M., and Hejazi S.H. "The Study of Capacity Enhancement of The Chabahar Gas Turbine Installation Using an Absorption Chiller," Applied Thermal Engineering, 2004, Vol.24, pp: 59-68.

10-Alhazmy, M.M., and Najjar Y.S.H." Augmentation of Gas Turbine Performance Using Air Coolers," Applied Thermal Engineering, 2004, Vol.24, is sues 2-3, pp: 415-429.

11-Bassily A.M., " Effect of Evaporative Inlet and After cooling on The Recuperated Gas Turbine Cycle," Applied Thermal Engineering, 2001, Vol.21, pp: 1875-1890.

12-Polyzakis A.L., Koroneos C., Xydis G. "Optimum Gas Turbine Cycle for Combined Cycle Power Plant" Energy Conversion and Management, 2008, Vol.49, pp: 551-556.

13-Cengel, A.Y. and Boles, A.M. "Thermodynamics and Engineering Approach", 2008, New York, McGraw-Hill.

14 -Naradasu R.K., Konigeti R.K., and Alluru V.R. "Thermodynamic analysis of heat recovery Steam Generation in Combined Cycle Power Plant" Thermal Science, 2007, V .11, No.4, pp:143-156. 


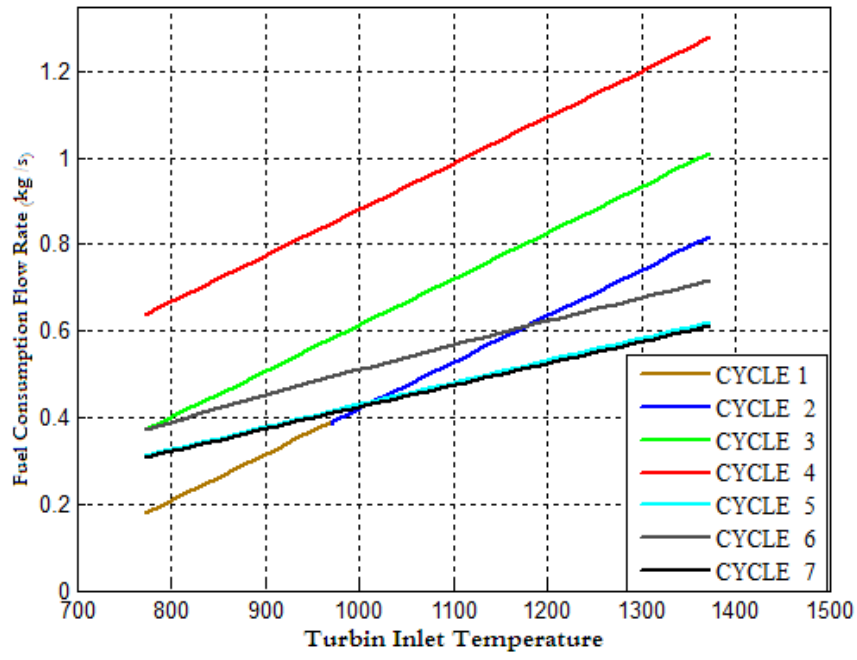

Fig. 8 (a) Represents The Effect Of Changing The Turbine Inlet Temperature On The Fuel Consumption Flow Rate Of The Different Gas Turbin cycles

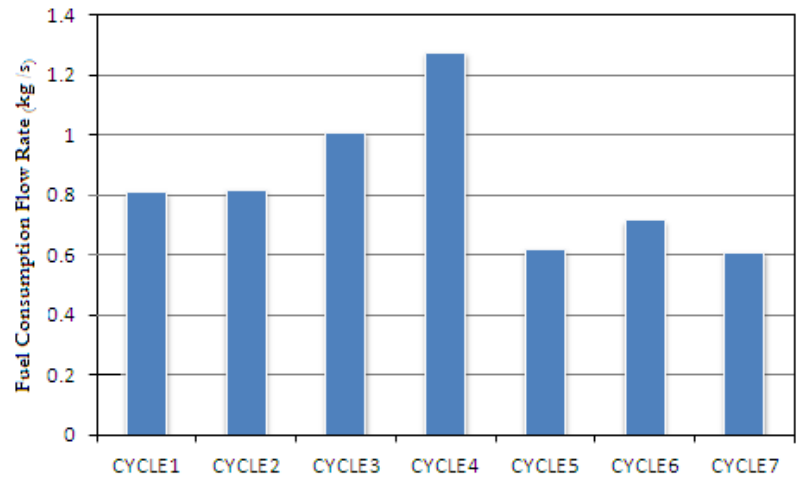

Fig. 8 (b) Represents The Maximum Fuel er Consumption Flow Rate Values Of The Different Gas Turbine Cycles At $T_{\text {gas }}=1373 \mathrm{k}$

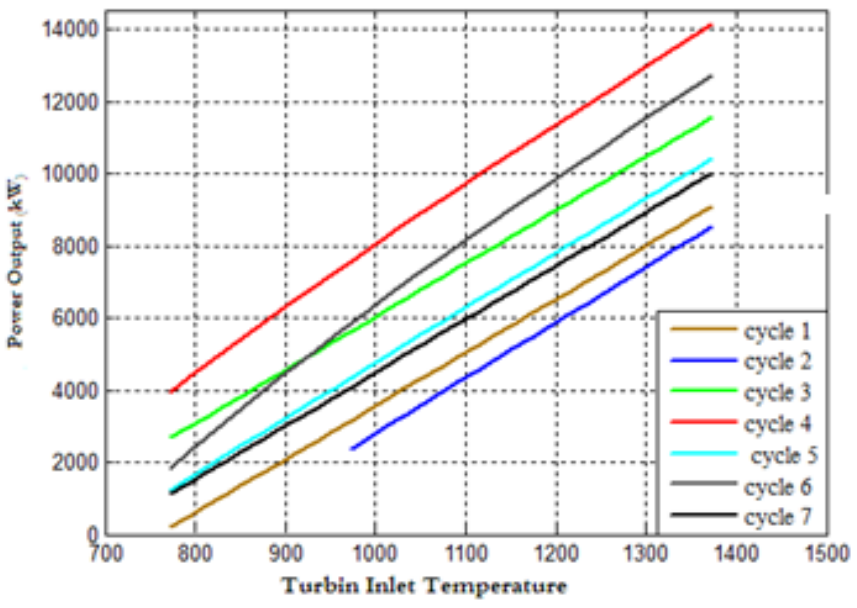

Fig. 9(a) Represents The Effect Of Changing The Turbine Inlet Temperature On The Power Output Of The Different Gas Turbin cycles

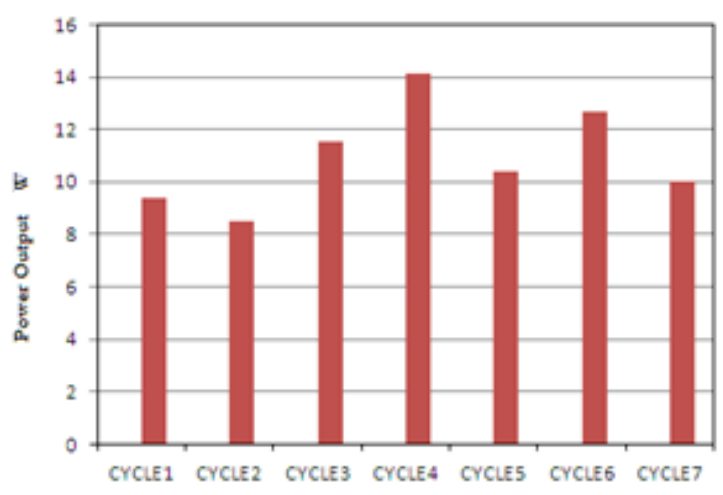

Fig. 9(b) Represents The Maximum Power Output Values of The Different Gas Turbine Cycles At $T_{\text {as }}=1373 \mathrm{k}$ 


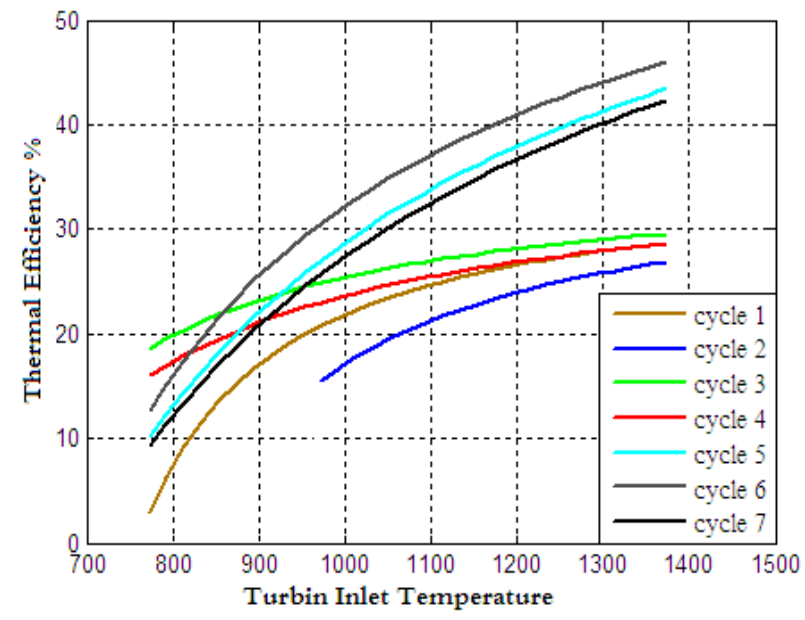

Fig. 10(a) Represents The Effect Of Changing The Turbine Inlet Temperature On The Thermal Efficiency of The Different Gas Turbin cycles

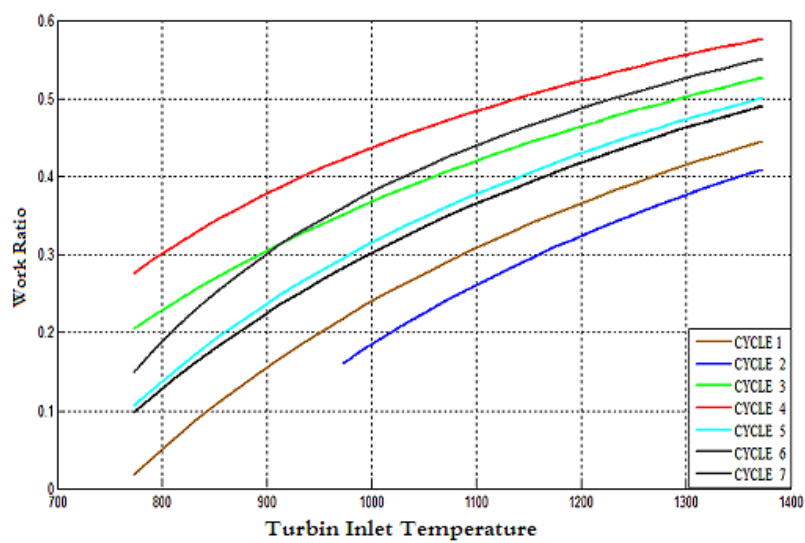

Fig. 11(a) Represents The Effect Of Changing The Turbine Inlet Temperature On The Work Ratio Of The Different Gas Turbin cycles

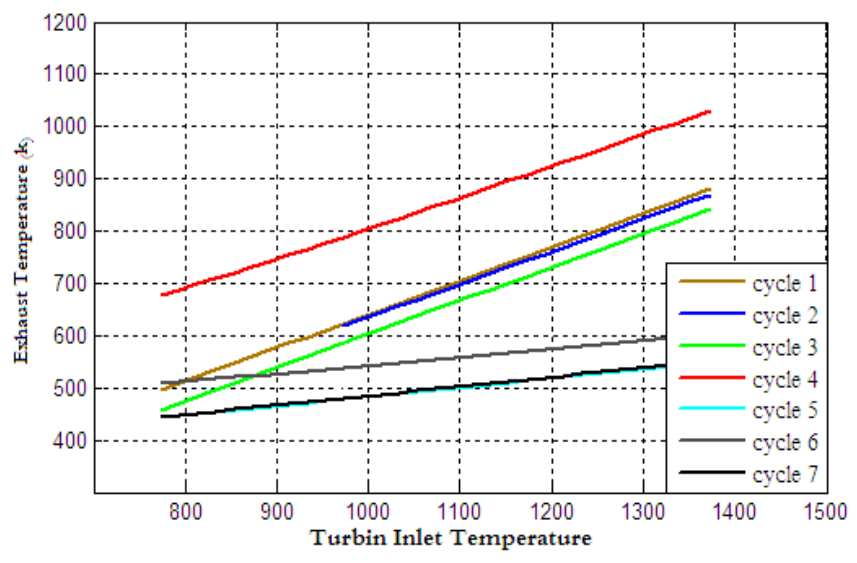

Fig. 12 (a) Represents The Effect Of Changing The

Turbine Inlet Temperature On The Exhaust Temperature Of The Different Gas Turbin cycles

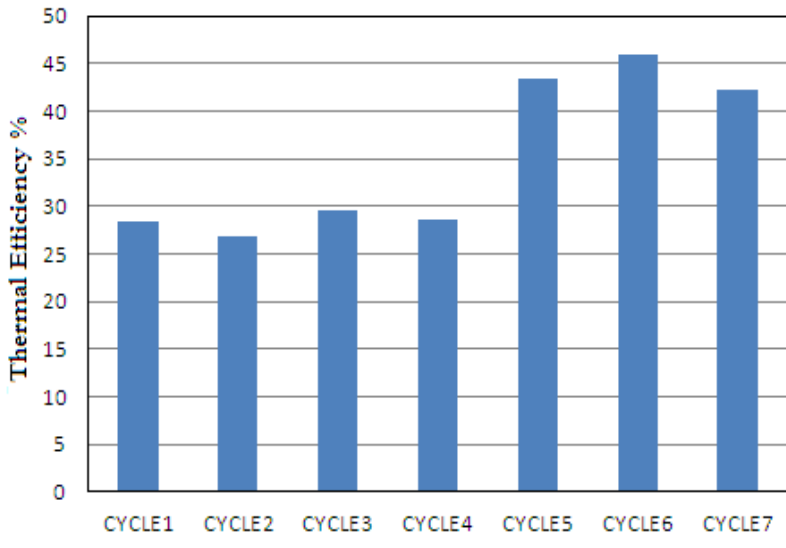

Fig.10(b) Represents The Maximum Thermal Efficiency Values Of The Different Gas Turbine Cycles At $T_{\text {gas }}=1373 \mathrm{k}$

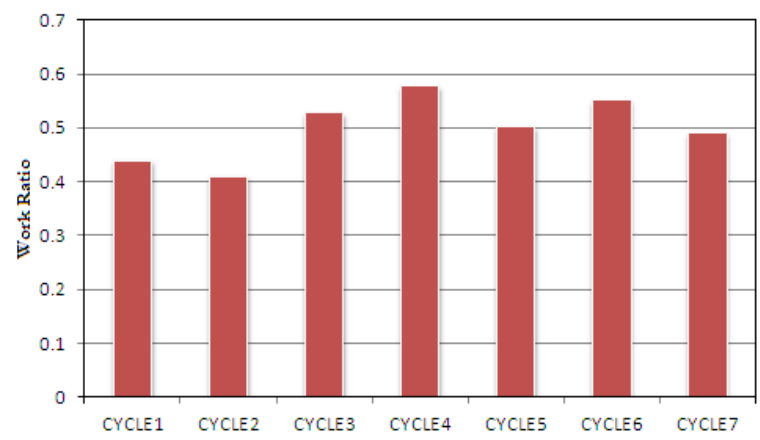

Fig.11(b) Represents The Maximum Work Ratio Values Of The Different Gas Turbine Cycles At $T_{\text {gas }}=1373 \mathrm{k}$

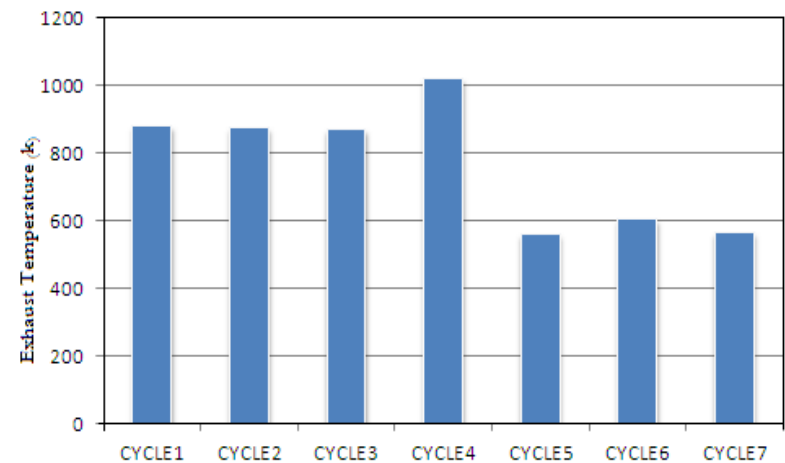

Fig.12(b) Represents The Maximum Exhaust Temperature Values of The Different Gas Turbine Cycles At $T_{\text {gas }}=1373 \mathrm{k}$ 


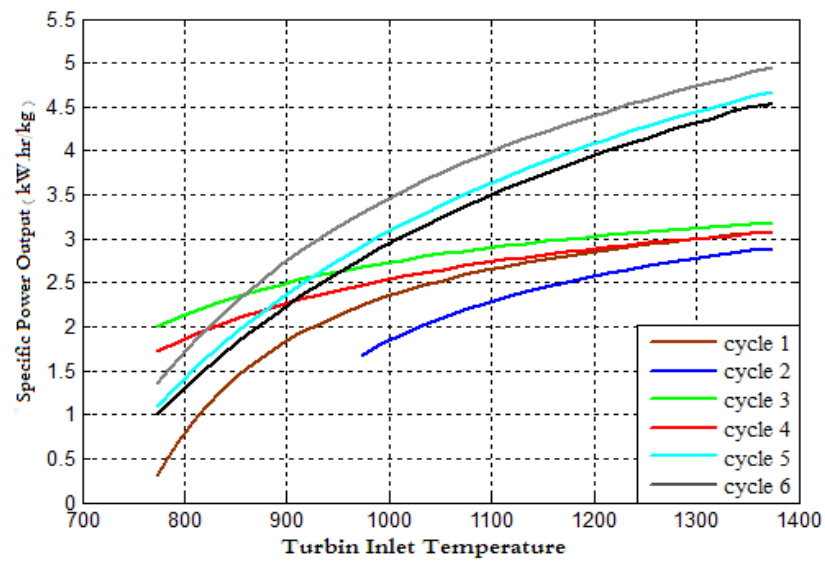

Fig. 13 (a) Represents The Effect Of Changing The Turbine Inlet Temperature On The Specific Power Output Of The Different Gas Turbin cycles

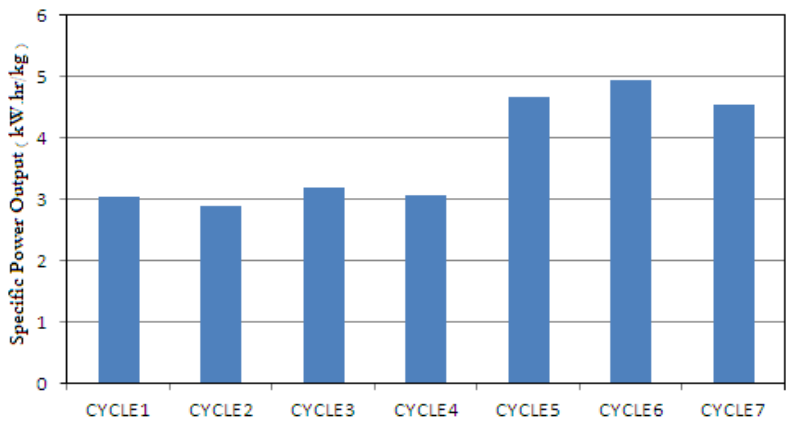

Fig. 13(b) Represents The Maximum Exhaust Temperature Values of The Different Gas Turbine Cycles At $T_{\text {gas }}=1373 \mathrm{k}$ 